\title{
Ausência de Trichinella spiralis em suínos adultos abatidos em Palmas, Estado do Paraná, Brasil
}

\author{
Absence of Trichinella spiralis in adult swines slaughtered \\ in Palmas, Paraná, Brazil
}

Heitor Daguer ${ }^{1}$ Pedro Valdir Geniz ${ }^{2}$ Adriano Vaz dos Santos ${ }^{2}$

\section{RESUMO}

Foram examinadas amostras de 3.774 suínos adultos, abatidos sob inspeção federal entre os anos de 2002 e 2004 na cidade de Palmas, Estado do Paraná, Brasil, utilizando-se a técnica da digestão artificial de amostras coletivas com agitador magnético para pesquisa de larvas de Trichinella spiralis. Os animais eram provenientes de 68 municípios dos três estados da região Sul do Brasil. A técnica utilizada seguiu as recomendações européias e as amostras examinadas consistiam de fragmentos musculares do masseter, base da língua e diafragma de cada animal. Não foram detectadas larvas do parasita nos animais examinados, sugerindo que a infecção por T. spiralis não ocorre nas criações de suínos examinadas.

Palavras-chave: Trichinella spiralis, suínos, inspeção, digestão artificial.

\section{ABSTRACT}

Samples of 3.774 adult pigs, slaughtered under federal inspection between the years of 2002 and 2004 in the county of Palmas, State of Paraná, Brazil, were examined by pooled sample artificial digestion with magnetic stirrer for a survey of Trichinella spiralis larvae. Animals proceeded from 68 counties of the three states of the South region of Brazil. The employed essay was the recommended by the European commission. The samples were formed by muscular pieces of masseter, tongue and diaphragm of each animal. No larvae were detected in the animals, indicating that $T$. spiralis infection does not occur in the examined swine stocks.

Key words: Trichinella spiralis, swine, inspection, artificial digestion.

\section{INTRODUÇÃO}

Os parasitas do gênero Trichinella spp. são nematódeos intracelulares capazes de infectar todos os carnívoros e onívoros de sangue quente, causando uma zoonose de ampla distribuição mundial, conhecida por triquinelose (GAMBLE, 1998). A espécie T. spiralis é a mais prevalente nas infecções humanas e os suínos domésticos constituem seu reservatório principal (DESPOMMIER et al., 2000). A infecção em suínos é adquirida por meio da sua alimentação com produtos de origem animal contaminados com o parasita, da sua exposição a roedores ou outros animais (principalmente silvestres) infectados com $\boldsymbol{T}$. spiralis e do canibalismo em granjas com animais infectados (GAMBLE, 1997; LIU \& BOIREAU, 2002). Em humanos, o principal mecanismo de transmissão é o consumo de carne suína crua ou mal cozida contendo larvas do parasita, mas produtos como salames, lingüiça e bacon, elaborados com carne suína contaminada, também podem funcionar como veículos da infecção (POZIO \& MARUCCI, 2003). No ser humano, o encistamento do parasita pode causar, entre diversos sintomas, fortes dores musculares e dificuldade respiratória, além da possibilidade de comprometimento do sistema nervoso (DESPOMMIER et al., 2000).

Em face dos prejuízos que pode causar à saúde pública, a triquinelose tem sido constante preocupação dos mais exigentes mercados consumidores

${ }^{1}$ Médico Veterinário, MSc, Serviço de Inspeção Federal n. 3094, Rua Ubirajara Araújo, 760, 85555-000, Palmas, PR, Brasil. Email: hdaguerffa@yahoo.com.br. Autor para correspondência.

${ }^{2}$ Agente de Inspeção, Palmali Industrial de Alimentos Ltda, Matadouro-Frigorífico, Palmas, PR, Brasil. 
de carne suína. A legislação da União Européia (Diretiva 77/96/CEE e Diretiva 84/319/CEE) determina que todos os suínos abatidos para consumo nos países pertencentes àquela comunidade sejam inspecionados para a presença de larvas de $\boldsymbol{T}$. spiralis (COMUNIDADE ECONÔMICA EUROPÉIA, 1977; COMUNIDADE ECONÔMICA EUROPÉIA, 1984). Com esta finalidade, diversos métodos diagnósticos têm sido empregados. A digestão artificial de amostras coletivas é um método direto que tem sido amplamente utilizado para detecção e controle de $\boldsymbol{T}$. spiralis em matadouros, sendo capaz de detectar a presença de larvas em 17 a 21 dias pós-infecção (GAMBLE, 1998). Em diversos países, a legislação sobre inspeção da carne suína tornou obrigatória a realização dessa técnica, que é ainda mais rápida e sensível do que a triquinoscopia, outro método direto tradicionalmente empregado (LIU \& BOIREAU, 2002; FORBES et al., 2003).

Algumas técnicas sorológicas (indiretas) como EIA (enzyme immunoassay) são capazes de detectar níveis de infecção muito baixos em suínos. No entanto, a soro-conversão só ocorre quatro a oito semanas após a infecção, o que faz com que esta técnica seja mais recomendada para a triagem de animais no ante mortem (GAMBLE, 1998), não devendo ser utilizada em substituição aos métodos diretos atualmente empregados para exame de carcaças de animais abatidos para consumo (GAMBLE et al., 2000; VAN KNAPEN, 2000).

No Brasil, não foram encontrados relatos de infecção por este parasita em animais e cidadãos brasileiros, apesar de ser endêmica em países vizinhos como Bolívia e Argentina (BJORLAND et al., 1993; VENTURIELLO et al., 1998).

O presente trabalho teve por objetivo realizar a pesquisa de larvas de $\boldsymbol{T}$. spiralis em suínos adultos, abatidos para consumo humano, visando à detecção de possíveis fontes de infecção deste parasita.

\section{MATERIAL E MÉTODOS}

Foram examinadas amostras de 3.774 suínos adultos com peso médio de $250 \mathrm{~kg}$, abatidos em matadouro-frigorífico sob inspeção federal localizado no município de Palmas, no sul do Estado do Paraná, Brasil, entre os meses de março/2002 e abril/2004. As amostras foram colhidas na sala de matança, logo após o abate dos animais, em recipientes identificados e numerados de forma a cada animal ter sua amostra depositada em um compartimento próprio. Para cada animal, a amostra constituiu-se de um fragmento do diafragma, um fragmento do masseter e um fragmento da base da língua.
As análises efetuadas constituíram-se da pesquisa de larvas de $\mathbf{T}$. spiralis pelo método da digestão artificial de amostras coletivas utilizando um agitador magnético e foram realizadas imediatamente após as coletas das amostras na sala de matança, em laboratório apropriado instalado na sede do serviço de inspeção do matadouro, seguindo-se a metodologia constante da Diretiva 77/96/CEE e subseqüentes alterações propostas pela União Européia (COMUNIDADE ECONÔMICA EUROPÉIA, 1977).

Foram analisados, simultaneamente, animais em número variável com a quantidade de suínos adultos disponíveis para abate no dia, sendo que cada conjunto de amostras (“pool”) desses animais pesava 100 g. O conjunto de amostras para digestão era constituído de três fragmentos musculares colhidos de cada animal (masseter, língua e diafragma). De acordo com a quantidade de animais examinados, esses fragmentos eram cortados, no laboratório, em fragmentos menores, de mesmo peso, nunca inferior a 1,01g, de forma que no máximo 33 suínos eram examinados por análise.

As amostras em “pool” eram trituradas rapidamente e submetidas à digestão com ácido clorídrico 25\% e pepsina 1:10.000 (National Formulary) à temperatura de $46^{\circ} \mathrm{C}$ por 30 minutos, sob agitação magnética. Concluída a digestão, todo o volume era vertido sobre peneira com malha de dimensão de $177 \mathrm{~mm}$, sendo o filtrado recolhido em ampola para que ocorresse a sedimentação por 30 minutos. Desprezava-se o sobrenadante e, após nova sedimentação por $10 \mathrm{mi}-$ nutos em proveta, o sedimento era recolhido e observado em placas de vidro ao estéreo-microscópio, com aumento de 40 vezes.

\section{RESULTADOS E DISCUSSÃO}

Não se detectou a presença de larvas de $\boldsymbol{T}$. spiralis nas amostras de tecidos musculares dos suínos examinados na presente pesquisa. Este resultado é concordante com outros trabalhos realizados no Brasil, como os de CATÃO et al. (1975) que examinaram 6.452 amostras de diafragma de suínos adultos pelo método de digestão em pepsina e ácido clorídrico e não observaram larvas do parasita em todas as amostras. Os animais procediam dos estados do Paraná (75,69\%), Minas Gerais (23,12\%), Goiás (0,91\%) e São Paulo (0,26\%). PAIM \& CÔRTES (1979) também não detectaram larvas do parasita em 594 diafragmas de roedores capturados na zona portuária de Santos, no Estado de São Paulo, pela técnica da triquinoscopia. Também não há quaisquer relatos de infecção por nenhuma espécie de Trichinella em locais como Porto Rico e Austrália (DESPOMMIER et al., 2000). 
A prevalência da infecção por $\mathbf{T}$. spiralis em suínos varia de país para país e regionalmente dentro dos países. As mais baixas prevalências em suínos domésticos são encontradas em países cujos programas de inspeção de carnes têm sido executados há muito tempo, como os países da União Européia (GAMBLE, 1997). Entretanto, segundo a Comissão Internacional sobre Triquinelose, até o momento não se pode fazer certificação de nenhum país, estado ou região como livres de $\boldsymbol{T}$. spiralis, devendo-se restringir a certificação às granjas produtoras para, no futuro, ser feita a certificação por regiões (GAMBLE et al., 2000).

No Brasil, embora a legislação para inspeção da carne suína tenha sido atualizada há poucos anos (BRASIL, 1995), apenas recentemente, com a expansão das exportações para a Rússia, reiniciou-se a pesquisa de $\mathbf{T}$. spiralis de forma rotineira nos matadouros de suínos. Esse procedimento era adotado de forma regular até 1945 nos matadouros brasileiros, quando então se interromperam os exames em função dos resultados negativos obtidos (CATÃO et al., 1975).

GAMBLE (1999) testou diversas variações na realização da técnica de detecção de $\boldsymbol{T}$. spiralis por digestão artificial de amostras coletivas, observando que o fator mais crítico era o tamanho da peneira. $\mathrm{O}$ autor sugere que sejam empregadas peneiras com abertura de 355mm, a fim de não afetar a passagem das larvas. No entanto, a peneira empregada na presente pesquisa é a exigida pela União Européia para utilização na inspeção de carnes suínas comercializadas naquela comunidade, sendo também empregada com sucesso pela comunidade científica (FORBES et al., 2003). GAMBLE et al. (1999) relatam que alguns países que adotaram essa técnica em seus programas de inspeção da carne suína alegam ter eliminado a infecção por T. spiralis de seus rebanhos. Segundo FORBES et al. (2003), tecidos musculares contendo altos níveis de larvas de $\boldsymbol{T}$. spiralis são facilmente detectados pela digestão artificial.

A técnica de digestão proposta pela União Européia prevê o exame de fragmentos do diafragma de, no máximo 100 animais por análise, com amostras individuais de, no mínimo 1g, para se formar o conjunto de $100 \mathrm{~g}$ de amostras. Alguns autores afirmam, contudo, que, em áreas onde a triquinelose é endêmica, cada fragmento componente do conjunto de amostras para digestão deve ter no mínimo $5 \mathrm{~g}$ a fim de não comprometer a detecção de larvas de $\mathbf{T}$. spiralis (GAMBLE, 1998; GAMBLE et al., 2000). Por outro lado, métodos de digestão artificial de amostras coletivas que empregam amostras individuais com peso mínimo 1g são geralmente considerados eficientes para detectar níveis de infecção nos animais capazes de causar a triquinelose clínica em humanos por meio da ingestão de carne crua ou mal cozida (GAMBLE et al., 2000).

De acordo com GAMBLE (1996), em suínos infectados, o diafragma e a língua acumulam números consideravelmente altos de larvas, em comparação a outros tecidos. Na presente pesquisa, cada animal examinado teve amostras de tecido muscular colhidas de três sítios (masseter, língua e diafragma), o que aumenta a probabilidade de detecção de eventuais larvas de T. spiralis. Foram examinados suínos de 68 municípios dos três estados da região Sul do Brasil, sendo 3.251 fêmeas (86,1\%) e 523 machos (13,9\%). Dos animais examinados, 72,2\% procediam de criações comerciais de 38 municípios do Estado do Paraná. Foram também examinados 233 suínos (6,2\%) provenientes de 11 municípios do Estado do Rio Grande do Sul e 815 suínos (21,6\%) provenientes de 19 municípios do Estado de Santa Catarina. Segundo VAN KNAPEN (2000), em áreas geográficas onde a triquinelose humana não tem sido relatada e onde os exames de animais em abatedouros sempre resultam negativos, a realização do exame rotineiro de carcaças em abatedouros é questionável, sendo ideal proceder-se ao monitoramento soro-epidemiológico em alternativa ao método direto.

\section{CONCLUSÕES}

O presente trabalho sugere que as criações de suínos examinadas não estão infectadas por larvas de T. spiralis, não significando risco à saúde pública. No entanto, outras pesquisas devem ser realizadas, inclusive por meio de técnicas sorológicas, a fim de dar maior embasamento à demonstração da possível inexistência da infecção por esse parasita nos rebanhos suínos desta e de outras regiões brasileiras. É necessário também se iniciar um programa de certificação de criações a partir de investigação epidemiológica. Os produtores de suínos da região devem ser alertados sobre a importância da preservação do atual perfil sanitário (livre de Trichinella spp), que muito contribuirá para a crescente projeção do Brasil como produtor e exportador de carne suína.

\section{REFERÊNCIAS BIBLIOGRÁFICAS}

BJORLAND, J. et al. Trichinella spiralis infection in pigs in the Bolivian Altiplano. Veterinary Parasitology, Amsterdam, v.47, n.3-4, p.349-354, 1993.

BRASIL. Ministério da Agricultura, do Abastecimento e da Reforma Agrária. Normas técnicas de instalações e equipamentos para abate e industrialização de suínos. Portaria 711 de 1 de novembro de 1995. Diário Oficial da União, Brasília, n.211, p.17625-17626, 1995. 
CATÃO, E. et al. Pesquisa de Trichinella spiralis em suínos abatidos para consumo em Minas Gerais. Arquivos da Escola de Veterinária da UFMG, Belo Horizonte, v.27, n.1, p.5557,1975 .

COMUNIDADE ECONÔMICA EUROPÉIA. Diretiva 77/96/ CEE. Jornal Oficial, Bruxelas, n.26, p.67-77, 1977.

COMUNIDADE ECONÔMICA EUROPÉIA. Diretiva 84/319/

CEE. Jornal Oficial, Bruxelas, n.167, p.34-43, 1984.

DESPOMIER, D.D. et al. Trichinella spiralis (Railliet 1896) In: Parasitic diseases. New York : Apple Trees, 2000. Cap.21, p.125-132.

FORBES, L.B. et al. Comparison of a modified digestion assay with trichinoscopy for the detection of Trichinella spiralis larvae in pork. Journal of Food Protection, Des Moines, v.66, n.6, p.1043-1046, 2003.

GAMBLE, H.R. Detection of trichinellosis in pigs by artificial digestion and enzyme immunoassay. Journal of Food Protection, Des Moines, v.59, n.3, p.295298, 1996.

GAMBLE, H.R. Parasites associated with pork and pork products. Revue scientifique et technique de l'Office Internationale des Epizooties, Paris, v.16, n.2, p.496-506, 1997.

GAMBLE, H.R. Sensitivity of artificial digestion and enzyme immunoassay methods for inspection of Trichinae in pigs. Journal of Food Protection, Des Moines, v.61, n.3, p.339343, 1998.

GAMBLE, H.R. Factors affecting the efficiency of pooled sample digestion for the recovery of Trichinella spiralis from muscle tissue. International Journal of Food Microbiology, Amsterdam, v.48, n.1, p.73-78, 1999.

GAMBLE, H.R. et al. Prevalence and risk association for Trichinella infection in domestic pigs in the northeastern United States. Veterinary Parasitology, Amsterdam, v.82, n.1, p.59-69, 1999.

GAMBLE, H.R. et al. International Commission on Trichinellosis: recommendations on methods for the control of Trichinella in domestic and wild animals intended for human consumption. Veterinary Parasitology, Amsterdam, v.93, n.3-4, p.393-408, 2000.

LIU, M.; BOIREAU, P. Trichinellosis in China: epidemiology and control. Trends in Parasitology, Londres, v.18, n.12, p.553-556, 2002

PAIM, G.V.; CÔRTES, V. Pesquisa de Trichinella spiralis em roedores capturados na zona portuária de Santos. Revista de Saúde Pública, São Paulo, v.13, p.54-55, 1979.

POZIO, E.; MARUCCI, G. Trichinella-infected pork products: a dangerous gift. Trends in Parasitology, Londres, v.19, n.8, p.338, 2003.

VAN KNAPEN, F. Control of trichinellosis by inspection and farm management practices. Veterinary Parasitology, Amsterdam, v.93, n.3-4, p.385-392, 2000.

VENTURIELLO, S.M. et al. Diagnosis of porcine trichinellosis: parasitological and immunoserological tests in pigs from endemic areas of Argentina. Veterinary Parasitology, Amsterdam, v.74, n.2-4, p.215-228, 1998. 